\title{
Research
}

\section{How widespread is working at scale in English general practice?}

\author{
An observational study
}

\begin{abstract}
\section{Background}

Over the last 5 years, national policy has encouraged general practices to serve populations of $>30000$ people lcalled working at scale') by collaborating with other practices.

\section{Aim}

To describe the number of English general practices working at scale, and their patient populations.
\end{abstract}

\section{Design and setting}

Observational study of general practices in England.

\section{Method}

Data published by the NHS on practices' selfreports of working in groups were supplemented with data from reports by various organisations and practice group websites. Practices were categorised by the extent to which they were working at scale; within these categories, the age distribution of the practice population, level of socioeconomic deprivation, rurality, and prevalence of longstanding illness were then examined.

\section{Results}

Approximately 55\% of English practices (serving

33.5 million patients) were working at scale. individually or collectively serving populations of $>30000$ people. Organisational models representing close collaboration for the purposes of core general practice services were identifiable for approximately $5 \%$ of practices; these comprised large practices, superpartnerships, and multisite organisations. Approximately $50 \%$ of practices were working in looser forms of collaboration, focusing on services beyond core general practice; for example, primary care in the evenings and at weekends. Data on organisational models and the purpose of the collaboration were very limited for this group.

\section{Conclusion}

In early 2018, approximately $5 \%$ of general practices were working closely at scale; approximately half of practices were working more loosely at scale. However, data were incomplete. Better records of what is happening at practice level should be collected so that the effect of working at scale on patient care can be evaluated.

\section{Keywords}

England; general practice; health policy: organisational models; primary health care.

\section{INTRODUCTION}

Over 7000 general medical practices deliver primary health care in England. ${ }^{1}$ For the last 70 years, the main organisational form of general practice has been the small private partnership of GPs, working in a single business unit, employing other staff.' When the NHS was established in 1948, practices with a single partner GP were the norm.? By 2017, practices had grown but were still small: the average number of partner GPs (full or part time) per practice was around three, and the average registered population was about 7000 people.

Although many practices have collaborated on a voluntary basis lfor example, in out-of-hours cooperatives, GP fundholding in the 1990s, and, more formally, in primary care trusts from 2000 until 2013), general practices are organisationally separate, with no routine contractual obligations to work together. NHS England's Five Year Forward View and the General Practice Forward View promoted further collaboration; the argument was that 'working at scale', as this has been called, will promote integrated care, innovation, staff development and organisational resilience, improve access to services, reduce costs, and give primary care a stronger voice. 4.5 The NHS Long Term Plan of January 2019 and the new general practice contract for $2019 / 2020^{6}$ set out

LJL Forbes, MSc (Public Health), MD, FFPH, senior clinical research fellow; S Peckham, BSc(Hons), MA, HMFPH, director and professor of health policy, Centre for Health Services Studies, University of Kent at Canterbury, Canterbury. H Forbes, BA, MSc, research associate; M Sutton, BA, MSc, PhD, chair in health economics; K Checkland, BMedSci, MRCGP, MA, PhD, professor of health policy and primary care, Division of Population Health, Health Services Research \& Primary Care, University of Manchester, Manchester.

Address for correspondence

Lindsay Forbes, University of Kent at Canterbury, plans for all practices to join primary care networks (PCNs): ${ }^{7}$ it will be mandatory for all practices to participate. ${ }^{6}$

Arguably, until early 2019, when detailed guidance on PCNs was published, there had been no specific organisational model for collaborative working between practices in England, with NHS England arguing that the model should depend on local circumstances. $5.8,9$ A number of models, with different ambitions and names (for example, mergers, superpartnerships, multisite organisations, multispecialty community providers, primary care homes, federations, networks, and alliances) have been implemented, 2,10-14 with many building on older groupings, relationships, and agreements between practices. ${ }^{14}$ Published surveys have suggested that $60-80 \%$ of general practices work in collaboration with others. ${ }^{11,15}$ One survey provided the names of collaborations, but offered limited information about how these were organised, the closeness of links, or their ambitions. ${ }^{15}$ Another survey provided more-detailed information, but the response rate was low. ${ }^{11}$

The size of collaboration proposed by NHS England has been 'at least' 30000 50000 registered patients, ${ }^{4,6,16}$ although evidence from the UK and elsewhere that any particular size of primary care organisation is better than any other is very limited. 13,14,17-19 Commentators have

Centre for Health Services Studies, George Allen Wing, Cornwallis Building, Giles Lane, Canterbury, Kent CT2 7NF, UK.

Email: L.Forbesakent.ac.uk

Submitted: 10 February 2019; Editor's response: 20 March 2019; final acceptance: 16 April 2019.

\section{CBritish Journal of General Practice}

This is the full-length article Ipublished online 10 Sep 2019) of an abridged version published in print. Cite this version as: Br J Gen Pract 2019; DOI: https://doi.org/10.3399/bjgp19X705533 


\section{How this fits in}

There are no firm data on the number of general practices working at scale in England, and which organisational models are being followed. This study found that close collaborations for the purposes of delivering core general practice served approximately $5 \%$ of the population and looser collaborations focusing on other services served approximately half of the population. However, data about these were very limited; it is important to ascertain what is happening at practice level to be able to evaluate working at scale.

argued that smaller practices offer better access, have better local focus, and may better meet the needs of some patient groups ${ }^{20}{ }^{2}$ The Care Quality Commission Ithe independent regulator of English health services) observed that, although bigger general practices appeared to deliver better care in general, many smaller practices that had a good knowledge of their population, planning of care to meet their needs, and good clinical networks, also delivered outstanding care. ${ }^{21}$

In preparation for a study on the impact of working at scale on quality of care, this study aimed to quantify the number of practices working at scale in England. General practice anecdotes suggest that some groups are strong and active, while others have little impact on the practice's work; as such, this study aimed to build on previous work to develop a comprehensive picture of working at scale, while also attempting to differentiate between those practices working substantively together and those between which the links were weaker.

\section{METHOD}

In January 2018, the authors requested data from NHS England regarding the extent of collaborations between practices with which it held contracts. Responding that it did not hold such data, it suggested looking at a survey it had carried out in September 2017 with the aim of understanding whether general practices were offering extended opening hours. ${ }^{22}$ As well as asking about extended access, the questionnaire asked What is the name of the group of which your practice is a member; for example, this could be the name of your federation? Only one free-text answer to this question was recorded. The dataset provided only the name of the group and no data on the type of group to which the practice belonged. It was not clear which member of the practice had completed the questionnaire. The decision was made, therefore, to seek to enrich the data with information on the type of group, according to the strength of the links between practices.

At this stage, it was not clear how the practices should be categorised. The groups listed in the NHS England survey described themselves using many different terms, such as federations, consortia, provider organisations, networks, alliances, membership organisations, companies, collaborations; or simply as groups with no data on organisational form, purpose, or closeness of links. As such, guidance was sought from other literature, namely:

- a systematic review of the impact of collaborations between general practices; $^{13}$

- an online article, in which a list of GP organisations working at scale had been collated by a journalist; ${ }^{15}$

- published reports about working at scale; ${ }^{11,14}$ and

- the websites of NHS England, the British Medical Association, the Royal College of General Practitioners, health policy think tanks the King's Fund and the Nuffield Trust, and the online magazines Pulse and GP Online.

This exercise also provided the names of other general practice groups; including information on organisational structure, purpose, and closeness of links for some. Using Google, two authors searched online for all the named groups to identify constituent practices and information on organisational form, purpose, and closeness of links. It became clear from this process that three distinct types of practice could be identified:

- those working closely at scale for the purposes of core general practice, with shared strategy and risk;

- those working loosely at scale to deliver services over and above core general practice only, such as extended access or specialist clinics in the primary care setting; and

- those apparently not working with other practices at all (not working at scale).

Working at scale was defined as serving a population of $>30000$ people, either as a single practice or as part of a group. Core general practice was defined as in the 
Figure 1. English general practices with $>1000$ patients, and collaboration types. aPractices with $>30000$ patients of whom $30 \%$ were aged $15-24$ years scale (to serve populations $>30000$ patients) as single practices or in collaborations with other practices. All numbers have been rounded so as not to overstate the precision of the estimates. The purple boxes represent practices working at scale. (assumed to be university practices). ${ }^{b}$ Working at

national contracts between NHS England and practices; namely, the management, during core hours, of patients: '... who are, or believe themselves to be: ill with conditions from which recovery is generally expected; terminally ill; or suffering from chronic disease ... 23,24

A list of all general practices in England was compiled according to whether they were working at scale. Those working at scale were further categorised according to whether they were working together (working closely at scale) for the purposes of core general practice, or for the purposes of services over and above core general practice only (working loosely at scale). Practices with $\leq 1000$ patients were excluded from the dataset as these tend to be either closing down or serve specific populations such as homeless people. The authors identified:

- whether practices were rural or urban;

- the proportion of patients aged 0-5 years and $\geq 75$ years; ${ }^{25}$

- the level of socioeconomic deprivation in the lower layer super output area of the main practice surgery postcode lusing the Index of Multiple Deprivation); ${ }^{1}$ and

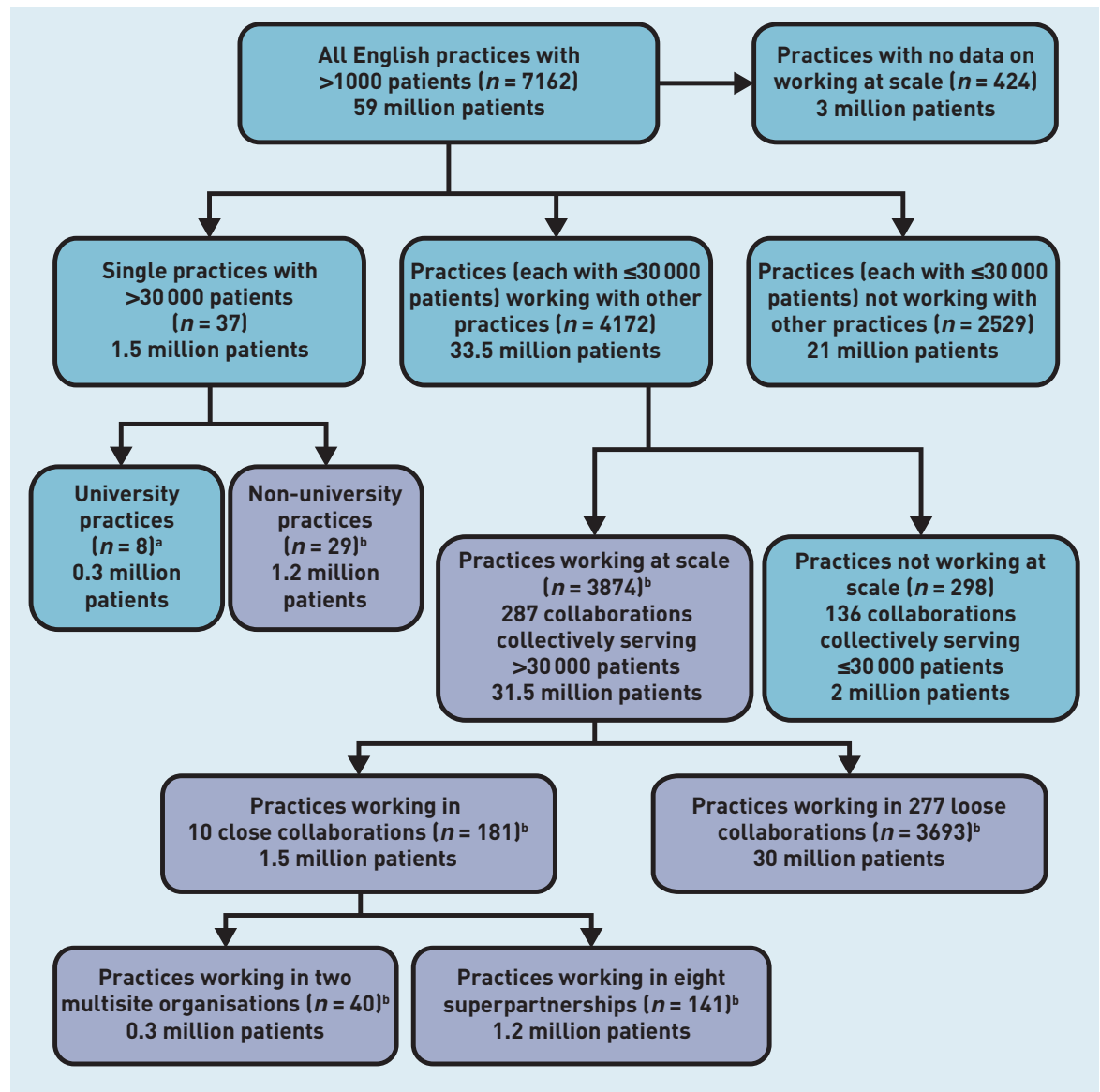

- the proportion who reported a limiting longstanding illness in the GP Patient Survey. ${ }^{26}$

The authors identified a separate group of university practices serving $>30000$ people as those in which $\geq 30 \%$ of the registered population was aged 15-24 years lusing demographic data on population served ${ }^{25}$ ); it is likely that these would be able to work at this scale as a result of low rates of lifelimiting chronic conditions among patients who may be resident in the area for only part of the year, rather than being able to deliver the benefits envisaged by national policy.

Differences in these factors between those practices working at scale for the purposes of core general practice, those working at scale for services over and above core general practice only, and those not working at scale were examined.

\section{RESULTS}

In February 2018, NHS England listed 7162 general practices with $>1000$ registered patients, each with a unique practice code. Figure 1 shows the number of practices and collaborations of different types, and indicates the total size of the population registered with each type.

Of these 7162 practices, $37(0.5 \%)$ were large single practices with $>30000$ registered patients, all working from multiple sites across a limited, definable geographical area lalthough, often there were other practices within the same geographical area that were not part of the large practice). Approximately 1.5 million people ( $2 \%)$ were registered with these large practices. Eight were university practices.

Of the 7125 practices with $\leq 30000$ registered patients, it was possible to find at least some information about group working for 6701 (94\%) practices; of these, 4172 $(62 \%)$ reported working as part of a group.

A total of 298 practices reported working in 136 groups that could not be defined as working at scale; that is, with collective populations of $\leq 30000$ patients. Approximately 2 million people were registered with these practices.

There were 3874 practices working in groups with collective registered populations of $>30000$ patients. Of these, 181 practices were working in 10 groups that could be classified as working in close collaboration for the purposes of core general practice. In these groups, individual practices retained practice contracts with NHS England and a degree of autonomy. ${ }^{14}$ Nine out of the 10 groups served $>50000$ patients, with the largest serving a population of $>300000$ 
as a group serving a population of $>30000$ patients only for the purposes of services over and above core general practice; and not working at scale). Compared with practices not working at scale, practices working at scale were more likely to be urban, had younger populations, slightly fewer patients with long-standing illnesses, and higher levels of socioeconomic deprivation. These differences were all statistically significant. The differences were more marked for practices working at scale to deliver core general practice than those working at scale to deliver only non-core general practice services.

\section{DISCUSSION}

\section{Summary}

In February 2018, approximately 55\% of the population registered with an English general practice was registered with a practice working at scale; in other words, serving a population of $>30000$ people, either individually or collectively. However, only $\sim 5 \%$ of the population was registered with a practice working at scale to deliver core general practice, in one of three organisational models: large practices, superpartnerships, and multisite organisations. Superpartnerships and multisite organisations often did not serve geographically neighbouring populations, although large practices did.

For practices working at scale in looser collaborations, serving just over half of the population, data on composition, purpose, and organisational model were limited, although the practices were mostly neighbours geographically. Where data were available, the purpose of the collaborations was to deliver services over and above core general practice. Many collaborations, of all kinds, were working together to deliver services for very large populations of $>50000$ patients. There was variation in practice and patient characteristics according to type of group: practices working at scale were less likely to be rural, had younger populations, and greater levels of socioeconomic deprivation.

\section{Strengths and limitations}

This study builds on previous work to identify the extent of working at scale over England. NHS England's survey about extended hours ${ }^{22}$ only allowed practices to cite one collaboration; given that the survey focused on extended access, many practices may not have provided complete data on collaborations. Moreover, there may be fewer groups than the dataset suggested because practices within the same group may have given different names for that group.

Some data sources, such as organisational websites, may not be reliable, and may not reflect current practice in a context of rapid change in group members and services. Therefore, the multiple collaborative links may not have been mapped fully. Data on websites relating to large practices, superpartnerships, and multisite organisations, were generally more comprehensive than data from websites relating to federations or other types of group. However, it is recognised that some federations or other types of group may have sophisticated functioning of which the authors were not be able to find documentary evidence.

The data sources did not identify certain other models of working at scale that are known to be operating. These include GP At Hand, which delivers digital remote services (https://www.gpathand.nhs.uk) and is reported to have $>30000$ patients registered, ${ }^{27}$ and a hospital-led model in Wolverhampton is reported to be providing general practice services for 70000 patients. ${ }^{28}$ Moreover, it did not reliably identify practices participating in the New Models of Care programme loutlined by the King's Fund ${ }^{29}$ ), which focuses on integration across whole local healthcare systems.

Some of the data sources used in this study were unreliable, which means that the extent of working at scale may have been under- or overestimated, both in terms of working closely together to provide core general practice, and in terms of lessformal arrangements to deliver benefits over and above the requirements of core general practice. One of the key problems in this regard is that practices may be part of more than one collaborative group, as shown in previous studies. ${ }^{11}$

\section{Comparison with existing literature}

It was found that working at scale was common, but not as common as suggested by a recent survey led by the Nuffield Trust of about 600 GPs and 50 staff employed by clinical commissioning groups (CCGs) that suggested that $80 \%$ of practices were working in formal or informal collaborations. The Nuffield Trust study had a low response rate (about $25 \%$ ) but it did provide rich data on the nature of collaborations in responding practices. ${ }^{11}$

A survey of CCGs by a journalist estimated that ' $70 \%$ of the country' was covered by some sort of 'scale GP group.' 15 However, that survey provided limited data on the nature of collaborations. 


\section{Implications for research and practice}

Understanding the extent of working at scale in general practice is the first step to evaluating the impact of different models of working at scale, and identifying the optimal size and appropriate models needed to tackle the challenges facing general practice. Evaluation needs to take into account practice and population characteristics. This study highlights many of the challenges of collecting data on working at scale in general practice and can be used to inform better ways of doing so.

It may be that small practices offer better continuity of care, especially for certain patient groups, such as people with multiple long-term conditions. Evidence from the US and Canada suggests that, in comparison with their larger counterparts, small practices may deliver benefits such as better patient experience, more cheaply, with fewer hospital admissions. ${ }^{19,30-32}$ Whether, however, these benefits are due to smaller organisational size, or other characteristics associated with a smaller registered population, is not known.

For some collaborations - especially some superpartnerships and multisite organisations - the geography of participating practices was not conducive to delivering population-based care, which requires knowledge of the needs of a defined population, with good clinical networks. ${ }^{4}$ Collaborations serving definable neighbouring geographical populations may be better placed to deliver population-based care. The less-formal collaborations working at scale did tend to cover geographically defined populations; many served very large populations, where achieving agreement between several partners to achieve efficiencies and deliver care according to need may be challenging.

It is generally believed that how general practice is currently organised is not sustainable or fit for purpose. However, the difficulty of sustaining general practice needs to be interpreted in light of pressure from demographic, social, and political forces, including the funding context, workforce, patient characteristics, and changing expectations. The traditional organisational model itself may not be the cause of the problem, nor working at scale the solution. In addition, what 'working at scale' actually means in practice is not clear, although the announcement in the new GP contract of a requirement for practices to join PCNs goes some way towards clarifying this. ${ }^{6}$ What remains very uncertain is how the new PCNs, which will go beyond general practice and attempt to integrate across community services, will be integrated with existing primary care organisations working at scale, especially when these are not defined by shared geography and links with other parts of the health and social care system. Tracking progress towards working at scale and defining what it means in practical terms are critical if the benefits and harms in relation to efficiency, workforce, patient experience, and quality of care, are to be
This research was funded by the National Institute of Health Research Policy Research Programme through the Policy Research Unit in Commissioning and the Healthcare System (PRUComm). The views expressed are those of the authors and not necessarily those of the NHS, the NIHR, the Department of Health and Social Care, or its arm's length bodies.

\section{Ethical approval}

Ethical approval was not required for this study.

\section{Provenance}

Freely submitted; externally peer reviewed.

\section{Competing interests}

The authors have declared no competing interests.

\section{Open access}

This article is Open Access: CC BY-NC 4.0 licence (http://creativecommons.org/ licences/by-nc/4.0/).

\section{Discuss this article}

Contribute and read comments about this article: bjgp.org/letters

\section{understood.}




\section{REFERENCES}

1. NHS Digital. General and Personal Medical Services, England: final 31 December 2017 and provisional 31 March 2018, experimental statistics. 2018. https://digital.nhs.uk/data-and-information/publications/statistical/ general-and-personal-medical-services/final-31-december-2017-andprovisional-31-march-2018-experimental-statistics (accessed 27 Aug 2019).

2. Baird B, Reeve H, Ross S, et al. Innovative models of general practice. 2018. https://www.kingsfund.org.uk/publications/innovative-models-general-practice laccessed 27 Aug 2019).

3. NHS England. NHS five year forward view. https://www.england.nhs.uk/ wp-content/uploads/2014/10/5yfv-web.pdf laccessed 27 Aug 2019).

4. NHS England. General practice forward view. 2014. https://www.england.nhs. uk/gp/gpfv/ laccessed 27 Aug 2019).

5. NHS England. Supporting sustainable general practice: a guide to networks and federations for general practice. 2016. https://www.england.nhs.uk/south/ wp-content/uploads/sites/6/2015/12/guide-netwrks-feds-gp.pdf laccessed 27 Aug 2019).

6. NHS England, British Medical Association. Investment and evolution: a five-year framework for gp contract reform to implement The NHS Long Term Plan. 2019. https://www.england.nhs.uk/wp-content/uploads/2019/01/ gp-contract-2019.pdf (accessed 27 Aug 2019).

7. NHS England. The NHS long term plan. 2019. https://www.longtermplan.nhs. uk/publication/nhs-long-term-plan laccessed 27 Aug 2019).

8. Connor R, Primary Care Transformation Programme. Supporting sustainable general practice: a guide to collaboration for general practice. 2016. https:// www.england.nhs.uk/south/wp-content/uploads/sites/6/2015/12/guidecollaboration-gp.pdf laccessed 27 Aug 2019).

9. NHS England. Supporting sustainable general practice: a guide to mergers for general practice. 2016. https://www.england.nhs.uk/south/wp-content/uploads/ sites/6/2015/12/guide-mergers-gp.pdf (accessed 27 Aug 2019).

10. Kumpunen S, Rosen R, Kossarova L, Sherlaw-Johnson C. Primary care home: evaluating a new model of primary care. 2017. https://www.nuffieldtrust.org. uk/research/primary-care-home-evaluating-a-new-model-of-primary-care laccessed 27 Aug 2019).

11. Kumpunen S, Curry N, Farnworth MJ, Rosen R. Collaboration in general practice: surveys of GP practices and clinical commissioning groups. 2017. https://www.nuffieldtrust.org.uk/files/2017-10/collaboration-in-generalpractice-2017-final.pdf laccessed 27 Aug 2019).

12. NHS England. The multispecialty community provider (MCP) emerging care model and contract framework. 2016. https://www.england.nhs.uk/wp-content/ uploads/2016/07/mcp-care-model-frmwrk.pdf laccessed 27 Aug 2019).

13. Pettigrew LM, Kumpunen S, Mays N, et al. The impact of new forms of largescale general practice provider collaborations on England's NHS: a systematic review. Br J Gen Pract 2018; DOI: https://doi.org/10.3399/bjgp18X694997.

14. Rosen R, Kumpunen S, Curry N, et al. Is bigger better? Lessons for large-scale general practice. 2016. https://www.nuffieldtrust.org.uk/research/is-biggerbetter-lessons-for-large-scale-general-practice laccessed 27 Aug 2019).

15. Thomas R. Analysis: England's Changing GP Landscape. Health Service Journal 2017; 5 Apr: https://www.hsj.co.uk/primary-care/analysis-englandschanging-gp-landscape-/7017089.article laccessed 27 Aug 2019).
16. NHS England. Next steps on the NHS five year forward view. 2017. https://uww. england.nhs.uk/wp-content/uploads/2017/03/NEXT-STEPS-ON-THE-NHSFIVE-YEAR-FORWARD-VIEW.pdf (accessed 27 Aug 2019).

17. $\mathrm{Ng} \mathrm{CWL}, \mathrm{Ng} \mathrm{KP}$. Does practice size matter? Review of effects on quality of care in primary care. Br J Gen Pract 2013; DOI: https://doi.org/10.3399/ bjgp13X671588.

18. Kelly E, Stoye G. Does GP practice size matter? GP practice size and the quality of primary care. 2014. https://www.ifs.org.uk/uploads/publications/comms/ R101.pdf laccessed 27 Aug 2019).

19. Casalino LP, Pesko MF, Ryan AM, et al. Small primary care physician practices have low rates of preventable hospital admissions. Health Aff (Millwood) 2014; 33(9): 1680-1688.

20. Mostashari F. The paradox of size: how small, independent practices can thrive in value-based care. Ann Fam Med 2016; 14(1): 5-7.

21. Care Quality Commission. The state of care in general practice 2014 to 2017: Findings from CQC's programme of comprehensive inspections of GP practices. 2017. https://www.cqc.org.uk/sites/default/files/20170921_state_of_ care_in_general_practice2014-17.pdf (accessed 27 Aug 2019).

22. NHS England. General Practice extended access data - September 2017. 2017 https://www.england.nhs.uk/statistics/statistical-work-areas/extended-accessgeneral-practice (accessed 27 Aug 2019).

23. NHS England. NHS England standard general medical services contract 2017/18. 2018. https://www.england.nhs.uk/wp-content/uploads/2018/01/17-18gms-contract.pdf laccessed 27 Aug 2019).

24. NHS England. NHS England standard Personal Medical Services agreement 2017/18. 2018. https://www.england.nhs.uk/wp-content/uploads/2018/01/17-18pms-contract.pdf laccessed 27 Aug 2019).

25. NHS Business Services Authority (NHSBSA). Population demographic data. Newcastle upon Tyne: NHSBSA, 2018.

26. NHS England. GP Patient Survey. Surveys \& Reports. 2017. https://umw. gp-patient.co.uk/surveysandreports2017 (accessed 27 Aug 2019).

27. Lind S. Scores of GP practices interested in GP at Hand collaboration, claims Babylon. Pulse 2018; 29 Aug: http://uww.pulsetoday.co.uk/news/gp-topics/ it/scores-of-gp-practices-interested-in-gp-at-hand-collaboration-claimsbabylon/20037367.article laccessed 27 Aug 2019).

28. Wickware C. Hospital in mass takeover of GP practices will soon have 70k patient list. Pulse 2017; 21 Jun: http://uww.pulsetoday.co.uk/news/gp-topics/ employment/hospital-in-mass-takeover-of-gp-practices-will-soon-have-70kpatient-list/20034631.article laccessed 27 Aug 2019).

29. Collins B. New care models: emerging innovations in governance and organisational form. 2016. https://www.kingsfund.org.uk/sites/default/files/field/ field_publication_file/New_care_models_Kings_Fund_Oct_2016.pdf laccessed 27 Aug 2019)

30. Robinson JC, Miller K. Total expenditures per patient in hospital-owned and physician-owned physician organizations in California. JAMA 2014; 312(16) 1663-1669

31. McWilliams JM, Chernew ME, Zaslavsky AM, et al. Delivery system integration and health care spending and quality for Medicare beneficiaries. JAMA Intern Med 2013: 173(15): 1447-1456.

32. Willis TA, West R, Rushforth $B$, et al. Variations in achievement of evidencebased, high-impact quality indicators in general practice: an observational study. PloS One 2017; 12(7): e0177949. 